\title{
Theory of Myth versus Meta-theory of Myth: On the Political Implications of a Late Twentieth-Century Distinction
}

\author{
Angus Nicholls
}

Due to rights restrictions, this chapter (pp. 219-232) is not available as an individual file in electronic format. It is a revised and extended version of Nicholls, A. (2018), review of Robert A. Segal, Myth: A Very Short Introduction, 2nd ed. In: Religion 48, no. 2, 316-321, reprinted by permission of Taylor \& Francis Ltd, http://www.tandfonline.com. 